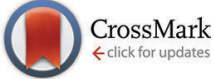

Cite this: Chem. Commun., 2016, 52, 2027

Received 14th November 2015, Accepted 2nd December 2015

DOI: $10.1039 / \mathrm{c5cc09446a}$ www.rsc.org/chemcomm

\section{Sequential meta-C-H olefination of synthetically versatile benzyl silanes: effective synthesis of meta-olefinated toluene, benzaldehyde and benzyl alcohols†}

\author{
Tuhin Patra, $\$$ Rahul Watile $\$$ Soumitra Agasti, Togati Naveen and Debabrata Maiti*
}

\begin{abstract}
Tremendous progress has been made towards ortho-selective $\mathrm{C}-\mathrm{H}$ functionalization in the last three decades. However, the activation of distal $\mathrm{C}-\mathrm{H}$ bonds and their functionalization has remained fairly underdeveloped. Herein, we report sequential meta-C-H functionalization by performing selective mono-olefination and bis-olefination with late stage modification of the $\mathrm{C}-\mathrm{Si}$ as well as $\mathrm{Si}-\mathrm{O}$ bonds. Temporary silyl connection was found to be advantageous due to its easy installation, easy removal and wide synthetic diversification.
\end{abstract}

The transition metal catalyzed functionalization of unactivated $\mathrm{C}-\mathrm{H}$ single bonds heralds the onset of a new era for the synthesis of complex molecular scaffolds, which being organic substances, display an undeniable presence of multiple $\mathrm{C}-\mathrm{H}$ bonds. ${ }^{1}$ Recent advances in the field of the regioselective conversion of $\mathrm{C}-\mathrm{H}$ bonds have widened the scope beyond the boundaries of classical catalytic cross-coupling reactions involving organohalides and the corresponding organometallic coupling partners. Moreover, a wise and prudential control of positional selectivity for $\mathrm{C}-\mathrm{H}$ activation in a molecule containing multiple $\mathrm{C}-\mathrm{H}$ bonds offers yet another outstanding challenge owing to its wide synthetic applications. An effective use of electronic bias ${ }^{2}$ and steric crowding ${ }^{3}$ for regioselectively functionalizing $\mathrm{C}-\mathrm{H}$ bonds in a molecule suffers from its own limitations, because it prevents functionalization of a less reactive $\mathrm{C}-\mathrm{H}$ bond. ${ }^{4}$ However, in an attempt to override such an intrinsic bias, different strategies have been undertaken, viz., $\sigma$-chelation-directed $\mathrm{C}-\mathrm{H}$ activation, which has been used as a potent technique for achieving ortho-selectivity. ${ }^{5,6}$ Although ortho-selective $\mathrm{C}-\mathrm{H}$ functionalization has been established in great depth over the last three decades, the selective functionalization of $\mathrm{C}-\mathrm{H}$ bonds located further away from the coordinating functional group remains a noteworthy challenge, ${ }^{7-10}$

Department of Chemistry, Indian Institute of Technology Bombay, Powai,

Mumbai-400076, India. E-mail: dmaiti@chem.iitb.ac.in

$\dagger$ Electronic supplementary information (ESI) available. See DOI: 10.1039/c5cc09446a

$\ddagger$ T. P. and R. W. contributed equally. especially when their locations do not permit cyclometallation subjected to geometric strain. Similarly, meta-selective functionalization, which has been achieved to date primarily for disubstituted arenes using steric and electronic control, ${ }^{11,12}$ has emerged as a prolific area of scientific interest. Over last few years, an alternate template-based approach ${ }^{13,14}$ for position selective meta-C-H activation has been reported. ${ }^{15}$ During our recent studies into the template-assisted meta-C-H activation of benzyl sulfonic acid, ${ }^{14}$ we were intrigued by the possibility to introduce a linker, which could be easily attached, easily removed and be versatile towards different synthetic transformations. ${ }^{16}$ In pursuit of this objective, ${ }^{16}$ herein, we report selective monoolefination and sequential bis-olefination at remote meta positions of benzyl silane using a nitrile-based template with post-synthetic diversification of silyl connection (Scheme 1).

Initially, this temporary silicon connection approach has been applied to restore superior regio- and stereo-selectivity by switching intermolecular reactions to intramolecular reactions. ${ }^{17}$ Later, Gevorgyan's group introduced these temporary silyl tethers for directed ortho-C-H activation followed by a high degree of diversification of the silyl moiety. ${ }^{18-20}$ We envisioned that the employment of a silyl-tethered directing group in place of a sulfonyl linker might be beneficial for meta-C-H activation

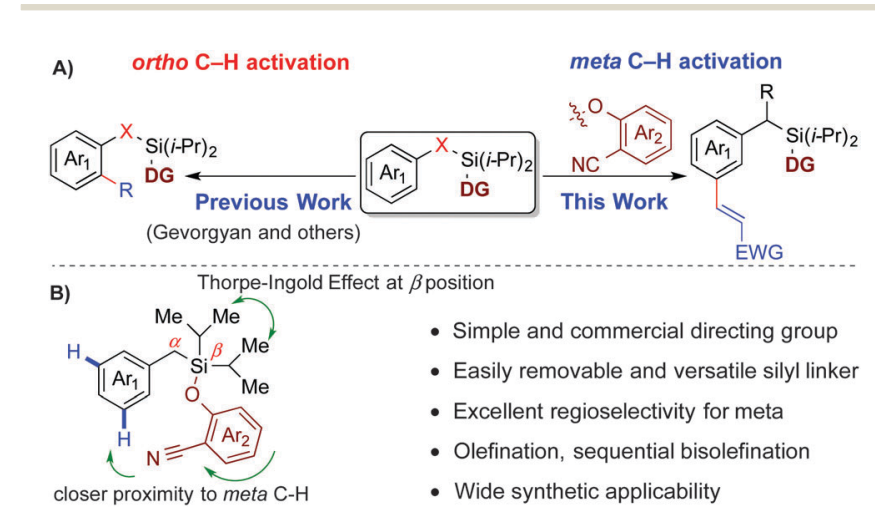

Scheme 1 (A) Ortho and meta- $\mathrm{C}-\mathrm{H}$ olefination of benzyl silane, (B) advantages of benzyl silyl ether. 


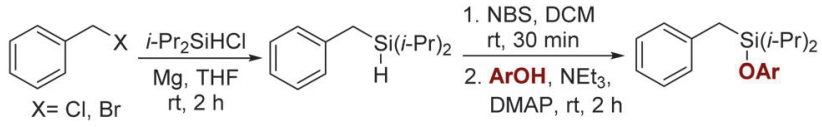

Scheme 2 Synthesis of directing template.

of an appended arene in two ways. First, the silyl tether can be removed easily. ${ }^{21}$ Second, the silyl tether has advantage of wide applicability in different synthetic transformations. ${ }^{1,22,23} \mathrm{We}$ hypothesized that the use of a simple 2-hydroxybenzonitrile ether of benzyl silanol may serve as an ideal choice for meta-C-H activation of the benzyl scaffold through linear coordination of the nitrile group (Schemes 1 and 2).

To test the hypothesis, benzyl diisopropylsilyl ether of 2-hydroxybenzonitrile was investigated with ethyl acrylate as a coupling partner. To our delight, the desired meta-olefinated product was observed in $72 \%$ yield with the meta selectivity of $>20: 1$ (mono: $\mathrm{di}=5: 1$ ). ${ }^{24}$ Upon extensive optimization and careful control of the electronic properties of cyanoarene derivatives, 2-hydroxy-5-methoxybenzonitrile was found to be the best directing group, producing $84 \%$ yield with a meta selectivity of $>20: 1$ (Scheme 3 , mono: $\mathrm{di}=7: 1){ }^{24}$

Initially, different benzyl derivatives were examined with methyl acrylate as the coupling partner in this optimized condition (Tables 1 and 2). The protocol was found to provide good to excellent yields, irrespective of the substituent position (ortho, meta, para or alpha). Diverse range of substituents, such as methyl, chloro, trifluoromethoxy, fluoro, bromo, trifluoromethyl, thiotrifluoromethyl, and methoxy are well tolerated under the reaction conditions (Table 1, entries $\mathbf{2 a - 2 h}$ ). Interestingly, Heck coupling or protodehalogenation was not observed for the halogenated arenes (entries 2d and 2g). Electronic (entries $\mathbf{2 c - 2 e}$ ) as well as steric bias (entry $\mathbf{2 j - 2 k}$ ) can be successfully overridden by this template-assisted approach.

Subsequently, the scope for olefin coupling partners was contemplated by varying a wide range of electron deficient alkenes. Vinylsulphonates (Table 2, entries $\mathbf{3 a}$ and $\mathbf{3 c}$ ) and alkyl vinyl ketone (entry $\mathbf{3 f}$ ) readily reacted to give the desired products. Acrylamide (entry $\mathbf{3 d}$ ) and vinylphosphonate (entry $3 \mathbf{e}$ ) provided good yields with the in situ removal of the template.

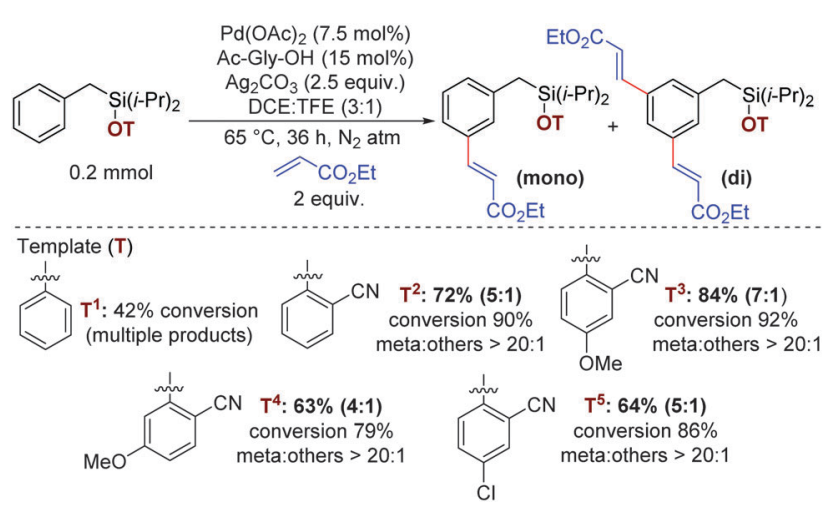

Scheme 3 Optimization of directing group.
Table 1 Benzyl scope for meta-C-H olefination ${ }^{24, a}$

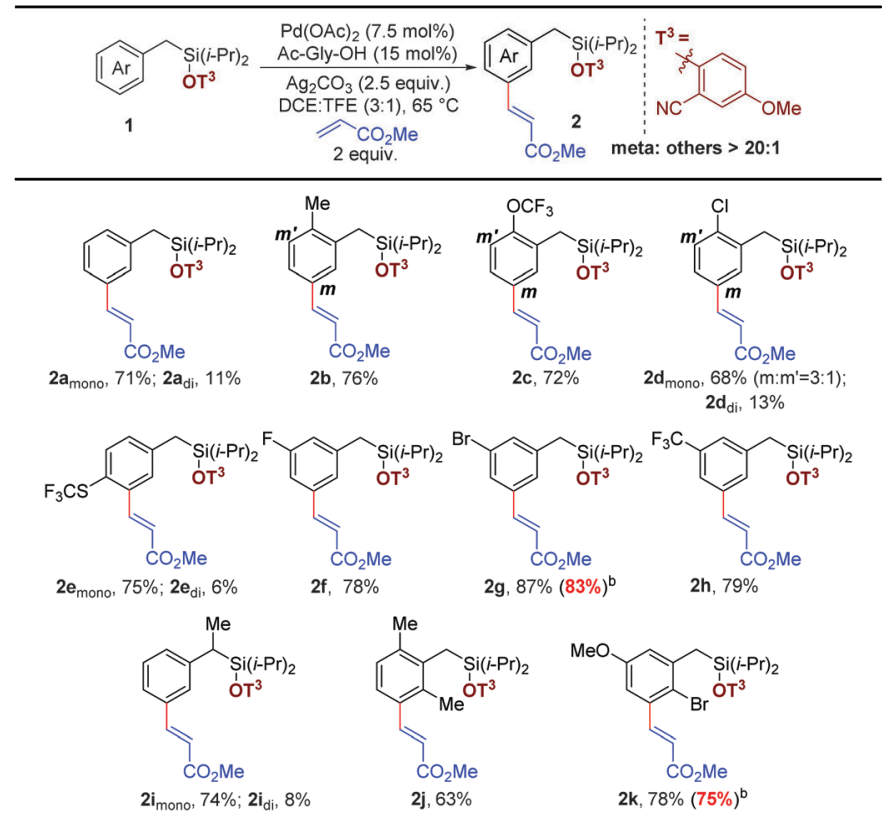

${ }^{a}$ All the reactions were carried out using $1(0.2 \mathrm{mmol})$, methyl acrylate $(0.4 \mathrm{mmol})$ in DCE/TFE $(1.2 / 0.4 \mathrm{~mL})$ for $24 \mathrm{~h}$ at $65{ }^{\circ} \mathrm{C} .{ }^{b} 2 \mathrm{mmol}$ scale.

Table 2 Olefin scope for meta-C-H olefination ${ }^{24, a}$

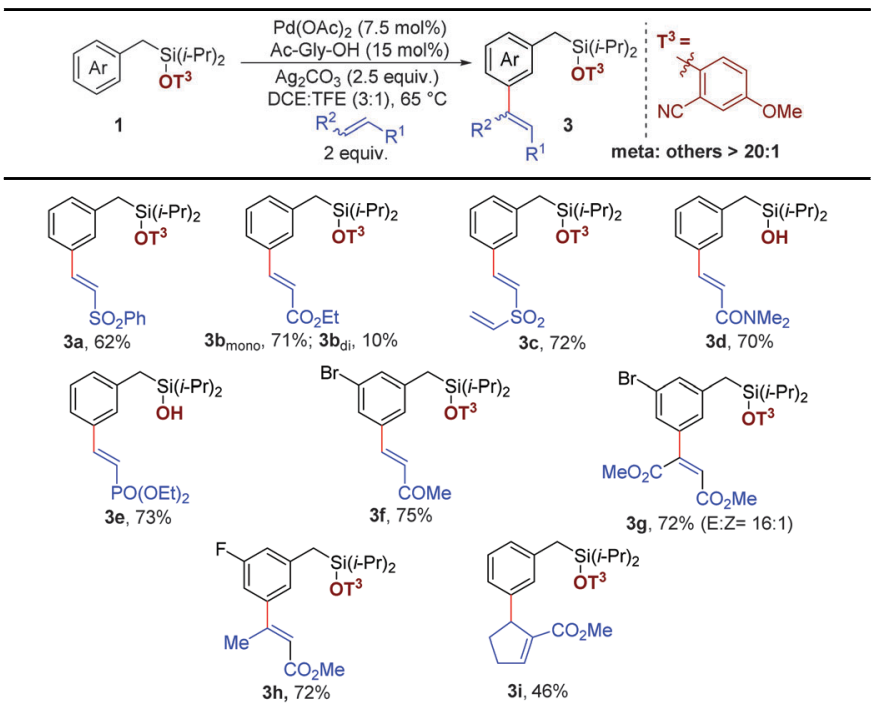

${ }^{a}$ All the reactions were carried out using $1(0.2 \mathrm{mmol})$, olefin $(0.4 \mathrm{mmol})$ in DCE/TFE $(1.2 / 0.4 \mathrm{~mL})$ for $24 \mathrm{~h}$ at $65{ }^{\circ} \mathrm{C}$.

Different 1,2-disubstituted acrylates can be employed successfully to obtain thermodynamically favorable trans isomer (Table 2, entries $\mathbf{3} \mathbf{g}$ and $\mathbf{3 h}$ ). Notably, cyclic tri-substituted olefins provided moderate yields with an expected allylic shift (entry $3 \mathbf{i}){ }^{25}$ High regioselectivity for meta isomer $(>20: 1)$ was obtained in all these cases, irrespective of the position and nature of the substituents and olefins.

During optimization and exploration of the substrate scope for meta-mono-olefination, we observed a high reactivity of this catalytic system because in some cases the diolefinated product 
Table 3 Scope for sequential meta-C-H bis-olefination ${ }^{24, a}$

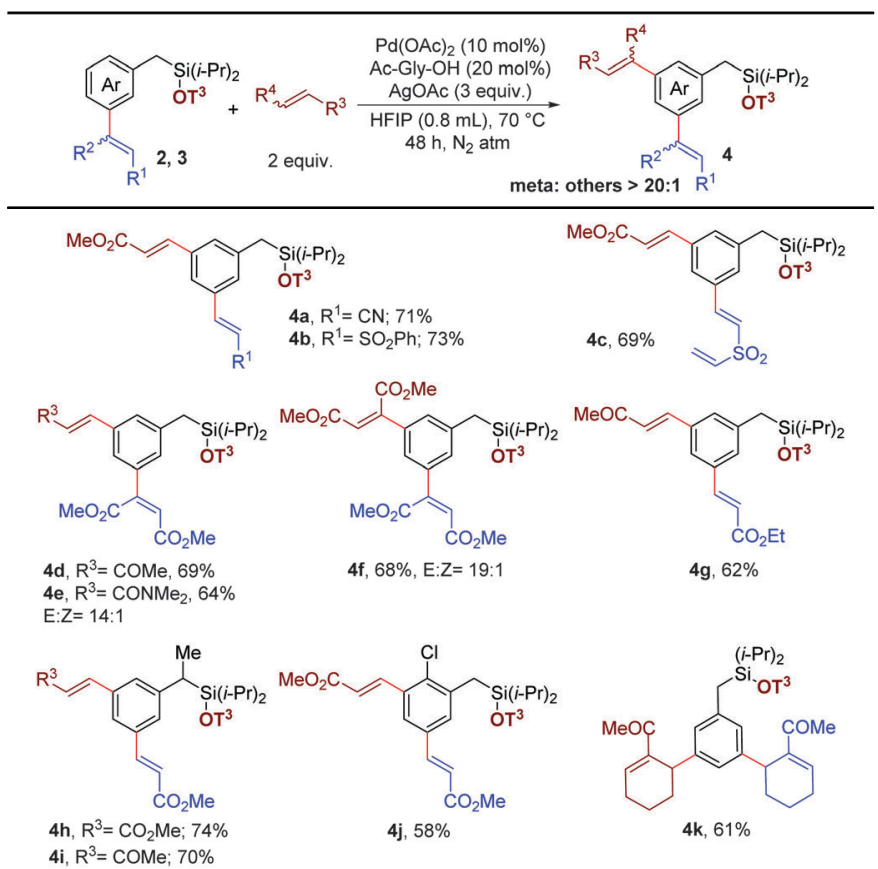

${ }^{a}$ All the reactions were carried out using 2 or $3(0.1 \mathrm{mmol})$, olefin $(0.2 \mathrm{mmol})$ in HFIP $(0.8 \mathrm{~mL})$ for $48 \mathrm{~h}$ at $70{ }^{\circ} \mathrm{C}$.

was obtained in a minor amount. Encouraged by such observations, an attempt was made for sequential bis-olefination, ${ }^{26}$ because divinylbenzene derivatives are widely used as building blocks in materials research and synthetic chemistry. ${ }^{27}$ Accordingly, the mono-olefinated product was examined for further olefination at the remaining meta position (Table 3). We were pleased to confirm that sequential bis-olefination indeed can be achieved in good yields under modified reaction conditions. A diverse set of olefins, such as acrylates (Table 3, entries $\mathbf{4 a}$ and $\mathbf{4 b}$ ), $\alpha, \beta$-unsaturated ketone (entries $\mathbf{4 d}, \mathbf{4 i}$ and $\mathbf{4 k}$ ), acrylamide (entry 4e), and disubstituted internal olefins (entry $\mathbf{4 f}$ ) were employed to provide moderate to good yields of bis-alkenylated products. Notably, sterically demanding ortho-substituted chlorobenzyl silyl ether also furnished the desired product (entry 4i). Even bulky tri-substituted cyclic olefin can be incorporated sequentially at both the meta positions of benzyl silyl ether (entry $\mathbf{4 k}$ ).

Next, to gain insights into the mode of action of this catalytic system, we performed an intermolecular competition experiment between 1a with two available meta positions and $1 \mathrm{~g}$ with only one site available for olefination. The product ratio clearly indicated that the rates of reaction for both cases are similar (Scheme 4).

This newly developed methodology with an easily cleavable $\mathrm{Si}-\mathrm{O}$ bond and a potentially modifiable $\mathrm{C}-\mathrm{Si}$ bond could serve as a means to conduct a myriad of synthetic diversifications. ${ }^{20,28}$

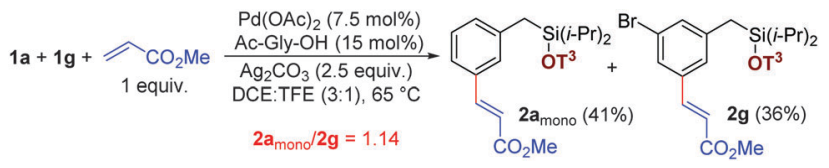

Scheme 4 Intermolecular competition experiment.

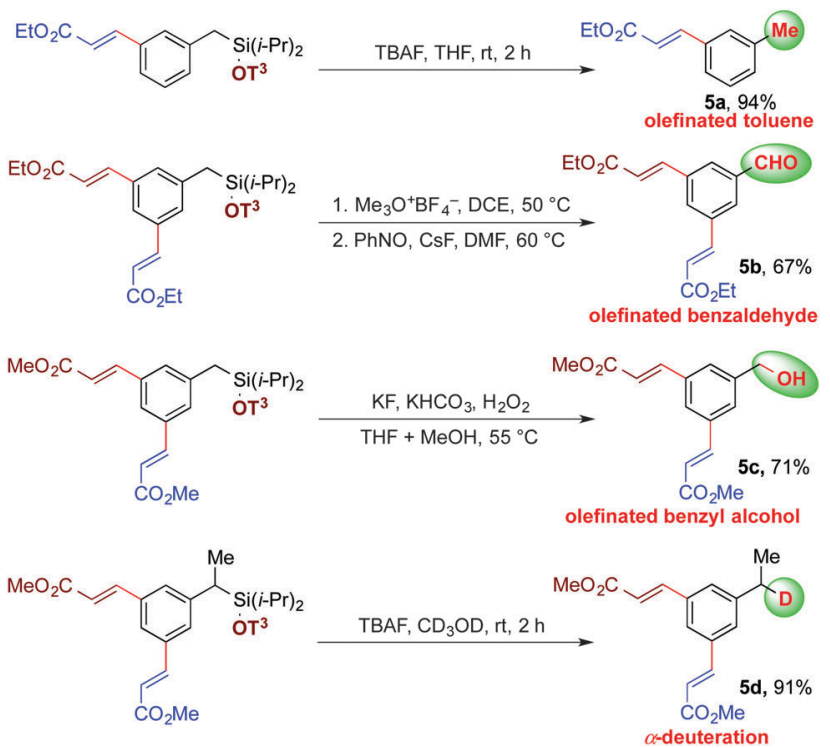

Scheme 5 Post-synthetic modifications of meta-C-H olefinated benzyl silyl ether.

Importantly, the silyl tether can be easily removed to provide olefinated toluene upon treatment of $n$-tetrabutyl ammonium fluoride (TBAF) in THF (Scheme 5, entry 5a). Meta-olefinated benzaldehyde can be obtained by modifying the same benzylic C-Si bond using nitrosobenzene as an oxidant (Scheme 5, entry 5b). Alternatively, the Fleming-Tamao oxidation of this $\mathrm{C}-\mathrm{Si}$ bond can deliver meta-olefinated benzyl alcohol under mild conditions (Scheme 5, entry 5c). ${ }^{29}$ Mono-deutereted toluene derivatives can be obtained selectively by simply changing the solvent from THF to methanol- $\mathrm{d}_{4}$ at the time of the silyl deprotection (Scheme 5, entry 5d).

After meta-olefination, the cyanophenol template can be removed easily, providing meta-olefinated benzyl silanol 6a. Subsequent ortho-olefination ${ }^{23}$ can be achieved on meta-olefinated benzyl silanol to obtain 2,5-diolefinated benzyl silanol (Scheme 6, entry 6b). Notably, 3,5-hetero diolefinated benzyl silane has been synthesized successfully (Table 3 ). Therefore, position selective 2,5- and 3,5-hetero diolefinated isomers can be achieved by applying the required sequence judiciously.

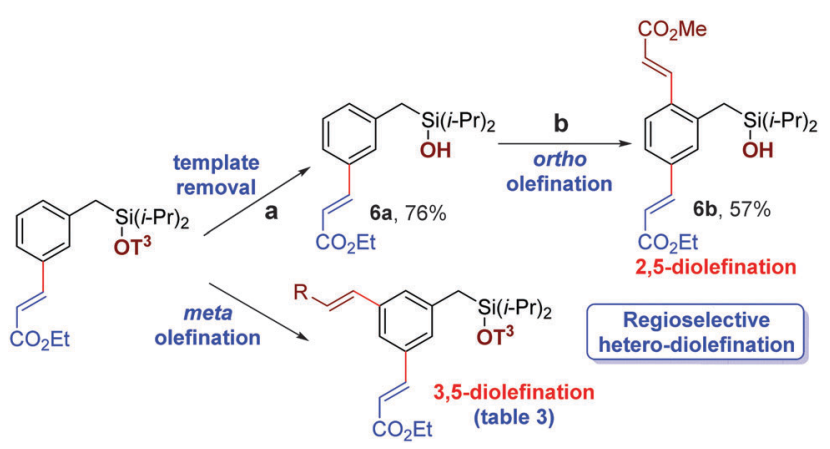

Scheme 6 Sequential 2,5- and 3,5-hetero di-olefination of benzyl silane. [a] TsOH (10 mol\%), ETOH/ $\mathrm{H}_{2} \mathrm{O}=1 / 1,90{ }^{\circ} \mathrm{C}, 12 \mathrm{~h}$. [b] Pd(OAc) 2 (20 mol\%), AgOAc (2 equiv.), $\mathrm{KH}_{2} \mathrm{PO}_{4}$ (2 equiv.), methyl acrylate (2 equiv.), $\mathrm{CHCl}_{3}$, $100{ }^{\circ} \mathrm{C}, 16 \mathrm{~h}$. 
In summary, the selective and efficient meta-C-H olefination of benzyl silane derivatives has been achieved with a simple and novel cyanophenol-based directing scaffold. Sequential olefination techniques were also developed for synthesizing valuable 2,5- and 3,5-hetero divinylbenzene derivatives exclusively. Meta-olefinated toluene, benzaldehyde and benzyl alcohol were also prepared easily upon removal of the silyl connection. Further synthetic applicability and detailed mechanistic investigations are currently underway.

This study was supported by SERB, India (EMR/2014/000164). Financial support received from UGC India (T. P.), IIT-B (R. W.) and CSIR India (S. A. and T. N.) are gratefully acknowledged.

\section{Notes and references}

1 (a) D. Y. K. Chen and S. W. Youn, Chem. - Eur. J., 2012, 18, 9452-9474; (b) J. Yamaguchi, A. D. Yamaguchi and K. Itami, Angew. Chem., Int. Ed., 2012, 51, 8960-9009; (c) P. Lu, Z. Gu and A. Zakarian, J. Am. Chem. Soc., 2013, 135, 14552-14555.

2 N. Kuhl, M. N. Hopkinson, J. Wencel-Delord and F. Glorius, Angew. Chem., Int. Ed., 2012, 51, 10236-10254.

3 For selected examples of $\mathrm{C}-\mathrm{H}$ activation by steric bias, see: (a) C. W. Liskey, X. Liao and J. F. Hartwig, J. Am. Chem. Soc., 2010, 132, 11389-11391; (b) Y. Saito, Y. Segawa and K. Itami, J. Am. Chem. Soc., 2015, 137, 5193-5198.

4 For $\mathrm{C}-\mathrm{H}$ activation by other approaches, see: $(a) \mathrm{J}$. Wencel-Delord, T. Droge, F. Liu and F. Glorius, Chem. Soc. Rev., 2011, 40, 4740-4761; (b) G. Menard and D. W. Stephan, Angew. Chem., Int. Ed., 2012, 51, 4409-4412; (c) G. Ménard, J. A. Hatnean, H. J. Cowley, A. J. Lough, J. M. Rawson and D. W. Stephan, J. Am. Chem. Soc., 2013, 135, 6446-6449; (d) D. Winkelhaus and D. W. Stephan, Angew. Chem., Int. Ed., 2014, 53, 5414-5417; (e) M. Tobisu and N. Chatani, Science, 2014, 343, 850-851; $(f)$ K. D. Collins, R. Honeker, S. VasquezCespedes, D.-T. D. Tang and F. Glorius, Chem. Sci., 2015, 6, 1816-1824; $(g)$ S. Vásquez-Céspedes, A. Ferry, L. Candish and F. Glorius, Angew. Chem., Int. Ed., 2015, 54, 5772-5776.

5 For selected reviews on ortho C-H activation, see: (a) C. G. Hartung and V. Snieckus, Modern Arene Chemistry, Wiley-VCH Verlag GmbH \& Co, KGaA, 2004, pp. 330-367; (b) X. Chen, K. M. Engle, D.-H. Wang and J.-Q. Yu, Angew. Chem., Int. Ed., 2009, 48, 5094-5115; (c) O. Daugulis, H.-Q. Do and D. Shabashov, Acc. Chem. Res., 2009, 42, 1074-1086; (d) T. W. Lyons and M. S. Sanford, Chem. Rev., 2010, 110, 1147-1169; (e) Y. Aihara and N. Chatani, J. Am. Chem. Soc., 2013, 135, 5308-5311; (f) G. Rouquet and N. Chatani, Angew. Chem., Int. Ed., 2013, 52, 11726-11743; (g) L. Ackermann, Acc. Chem. Res., 2014, 47, 281-295.

6 (a) K. M. Engle, T.-S. Mei, M. Wasa and J.-Q. Yu, Acc. Chem. Res., 2012, 45, 788-802; (b) Z. Chen, B. Wang, G. Zhu and J. Sun, Angew. Chem., Int. Ed., 2013, 52, 2027-2031; (c) W. Zhao, Z. Wang, B. Chu and J. Sun, Angew. Chem., Int. Ed., 2015, 54, 1910-1913.

7 (a) X.-C. Wang, W. Gong, L.-Z. Fang, R.-Y. Zhu, S. Li, K. M. Engle and J.-Q. Yu, Nature, 2015, 519, 334-338; (b) Z. Dong, J. Wang and G. Dong, J. Am. Chem. Soc., 2015, 137, 5887-5890.

8 (a) O. Saidi, J. Marafie, A. E. W. Ledger, P. M. Liu, M. F. Mahon, G. Kociok-Kohn, M. K. Whittlesey and C. G. Frost, J. Am. Chem. Soc., 2011, 133, 19298-19301; (b) N. Hofmann and L. Ackermann, J. Am. Chem. Soc., 2013, 135, 5877-5884; (c) C. J. Teskey, A. Y. W. Lui and M. F. Greaney, Angew. Chem., Int. Ed., 2015, 54, 11677-11680.

9 (a) J. Cornella, M. Righi and I. Larrosa, Angew. Chem., Int. Ed., 2011, 50, 9429-9432; (b) F. Juliá-Hernández, M. Simonetti and I. Larrosa, Angew. Chem., Int. Ed., 2013, 52, 11458-11460; (c) B. J. Groombridge,
S. M. Goldup and I. Larrosa, Chem. Commun., 2015, 51, 3832-3834; (d) J. Luo, S. Preciado and I. Larrosa, Chem. Commun., 2015, 51, 3127-3130.

10 Y. Kuninobu, H. Ida, M. Nishi and M. Kanai, Nat. Chem., 2015, 7, 712-717.

11 (a) J.-Y. Cho, M. K. Tse, D. Holmes, R. E. Maleczka and M. R. Smith, Science, 2002, 295, 305-308; (b) T. Ishiyama, J. Takagi, K. Ishida, N. Miyaura, N. R. Anastasi and J. F. Hartwig, J. Am. Chem. Soc., 2002, 124, 390-391.

12 (a) Y.-H. Zhang, B.-F. Shi and J.-Q. Yu, J. Am. Chem. Soc., 2009, 131, 5072-5074; (b) R. J. Phipps and M. J. Gaunt, Science, 2009, 323, 1593-1597.

13 (a) D. Leow, G. Li, T.-S. Mei and J.-Q. Yu, Nature, 2012, 486, 518-522; (b) H.-X. Dai, G. Li, X.-G. Zhang, A. F. Stepan and J.-Q. Yu, J. Am. Chem. Soc., 2013, 135, 7567-7571; (c) L. Wan, N. Dastbaravardeh, G. Li and J.-Q. Yu, J. Am. Chem. Soc., 2013, 135, 18056-18059; (d) R.-Y. Tang, G. Li and J.-Q. Yu, Nature, 2014, 507, 215-220; (e) G. Yang, P. Lindovska, D. Zhu, J. Kim, P. Wang, R.-Y. Tang, M. Movassaghi and J.-Q. Yu, J. Am. Chem. Soc., 2014, 136, 10807-10813; $(f)$ Y. Deng and J.-Q. Yu, Angew. Chem., Int. Ed., 2015, 54, 888-891; $(g)$ S. Lee, H. Lee and K. L. Tan, J. Am. Chem. Soc., 2013, 135, 18778-18781; (h) M. Bera, A. Modak, T. Patra, A. Maji and D. Maiti, Org. Lett., 2014, 16, 5760-5763.

14 M. Bera, A. Maji, S. K. Sahoo and D. Maiti, Angew. Chem., Int. Ed., 2015, 54, 8515-8519.

15 (a) J. Schranck, A. Tlili and M. Beller, Angew. Chem., Int. Ed., 2014, 53, 9426-9428; (b) S. Li, H. Ji, L. Cai and G. Li, Chem. Sci., 2015, 6, $5595-5600$

16 S. Bag, T. Patra, A. Modak, A. Deb, S. Maity, U. Dutta, A. Dey, R. Kancherla, A. Maji, A. Hazra, M. Bera and D. Maiti, J. Am. Chem. Soc., 2015, 137, 11888-11891.

17 G. Stork, H. S. Suh and G. Kim, J. Am. Chem. Soc., 1991, 113, 7054-7056.

18 (a) C. Huang, B. Chattopadhyay and V. Gevorgyan, J. Am. Chem. Soc., 2011, 133, 12406-12409; (b) C. Huang, N. Ghavtadze, B. Chattopadhyay and V. Gevorgyan, J. Am. Chem. Soc., 2011, 133, 17630-17633.

19 (a) A. V. Gulevich, F. S. Melkonyan, D. Sarkar and V. Gevorgyan, J. Am. Chem. Soc., 2012, 134, 5528-5531; (b) D. Sarkar, F. S. Melkonyan, A. V. Gulevich and V. Gevorgyan, Angew. Chem., Int. Ed., 2013, 52, 10800-10804.

20 C. Huang, N. Ghavtadze, B. Godoi and V. Gevorgyan, Chem. - Eur. J., 2012, 18, 9789-9792.

21 E. J. Corey and A. Venkateswarlu, J. Am. Chem. Soc., 1972, 94, 6190-6191.

22 N. Chernyak, A. S. Dudnik, C. Huang and V. Gevorgyan, J. Am. Chem. Soc., 2010, 132, 8270-8272.

23 C. Wang and H. Ge, Chem. - Eur. J., 2011, 17, 14371-14374.

24 See the Supporting Information for detailed description.

25 G. T. Crisp, Chem. Soc. Rev., 1998, 27, 427-436.

26 (a) A. S. Carlstroem and T. Frejd, J. Org. Chem., 1991, 56, 1289-1293; (b) K. M. Engle, D.-H. Wang and J.-Q. Yu, Angew. Chem., Int. Ed., 2010, 49, 6169-6173; (c) A. Deb, S. Bag, R. Kancherla and D. Maiti, J. Am. Chem. Soc., 2014, 136, 13602-13605.

27 (a) J. H. Burroughes, D. D. C. Bradley, A. R. Brown, R. N. Marks, K. Mackay, R. H. Friend, P. L. Burns and A. B. Holmes, Nature, 1990, 347, 539-541; (b) A. Kraft, A. C. Grimsdale and A. B. Holmes, Angew. Chem., Int. Ed., 1998, 37, 402-428; (c) A. C. Grimsdale, K. Leok Chan, R. E. Martin, P. G. Jokisz and A. B. Holmes, Chem. Rev., 2009, 109, 897-1091.

28 (a) A. Ricci, M. Fiorenza, M. A. Grifagni, G. Bartolini and G. Seconi, Tetrahedron Lett., 1982, 23, 5079-5082; (b) K. Itami, M. Mineno, T. Kamei and J.-i. Yoshida, Org. Lett., 2002, 4, 3635-3638.

29 K. Tamao, M. Kumada and K. Maeda, Tetrahedron Lett., 1984, 25, 321-324. 